\title{
MEMPERSIAPKAN BISNIS ONLINE BAGI PRODUK SASIRANGAN DI KELURAHAN SUNGAI MESA KOTA BANJARMASIN
}

\author{
Basuki, Zakky Zamrudi, dan Hairul \\ Fakultas Ekonomi, Universitas Islam Kalimantan \\ Email : msibasukidr@gmail.com
}

\begin{abstract}
Sasirangan cloth industry continue to grow through Banjarmasin and South Kalimantan in general. Supporting of the government and the other parties, sasirangan industry be one of locomotion economic the people who could not being taken from granted. Almost hundreds of home industries have good scale, micro and small thrives in South Kalimantan income of a whole reach millions until even billions of rupiah per month. Increasing competition in cloth industry they need to in open opportunities marketing via internet. Basically between business online and the internet marketing have in common meaning or similar signification, same has objective to earn a living through digital world. But for the internet marketing more oriented to techniques get money from the online business.
\end{abstract}

Keywords: Online Business, Marketing, Sasirangan home industy

\section{PENDAHULUAN}

Industri kain sasirangan terus berkembang di Banjarmasin maupun Kalimantan Selatan (Kalsel) secara umum. Dengan dukungan pemerintah dan berbagai pihak, industri sasirangan menjadi satu di antara penggerak ekonomi masyarakat yang tidak bisa disepelekan.

Ratusan industri baik berskala rumahan, mikro dan kecil tumbuh subur di Kalsel dengan omzet keseluruhan mencapai ratusan juta bahkan miliaran rupiah per bulan. Pesatnya perkembangan industri sasirangan, tidak bisa dipungkiri persaingan di industri kain khas Banua ini kian ketat. Para pengrajin dan produsen kain sasirangan harus putar otak untuk bisa memiliki nilai lebih dan keunikan sebagai modal bersaing di industri sasirangan.

Semenjak diperkenalkan pertama kalinya di tahun 1994, hingga kini perkembangan bisnis online semakin pesat. Bisnis online yang semula hanya dipakai untuk tujuan promosi dan periklanan melalui halaman website, kini telah berubah menjadi bisnis yang multifungsi, baik sebagai sarana promosi, pembelian barang, penjualan barang, dan juga penjualan jasa-jasa lainnya yang dilakukan melalui sistem online. 
Bagi para pemula, merancang sebuah pemasaran online itu pasti terasa sulit karena tidak tahu harus melakukan apa dan dari mana harus memulainya. Sebenarnya ada beberapa tutorial online yang mengajarkan tentang cara memulai bisnis online tertentu. Sebaiknya kita mengetahui dan menentukan jenis bisnis online seperti apa yang akan dijalankan karena model bisnis online itu sebenarnya sangat banyak dengan tingkat kesulitan yang berbeda-beda.

Berdasarkan penjelasan di atas, sehingga perlu dijelaskan terlebih dahulu bagaimana merancang sebuah pemasaran online agar produk dapat dikenal calon konsumen secara virtual.

Memasarkan suatu produk dapat melalui berbagai saluran, bisa langsung dari produsen ke konsumen, bisa melalui agen atau distributor dan bisa juga melalui pemasaran online. Pemasaran online dapat dilakukan apabila pemilik usaha telah mempunyai akun, blog ataupun website sendiri. Namun demikian, tidak semua pengusaha apalagi pengrajin yang sudah mengenal pemasaran online tersebut.

Produk kerajinan seringkali dihadapkan pada berbagai permasalahan, diantaranya adalah jumlah produksi yang terbatas dan tidak menentu, penetapan harga jual yang tidak ekonomis, skala usaha yang bervariasi dan diferensiasi produk yang sangat fluktuatif diantara pengrajin.

Tujuan dari kegiatan ini adalah untuk memberikan pengetahuan dan teknik-teknik pemasaran online bagi industri rumah tangga pengrajin sasirangan di Kota Banjarmasin terutama di kelurahan Sungai Mesa.

\section{KHALAYAK SASARAN}

Kelompok pengrajin yang ada di kelurahan Sungai Mesa Kota Banjarmasin yang memiliki kegiatan membuat kerajinan kain sasirangan di wilayah tersebut. Usaha ini telah dijalan cukup lama, untuk mengisi waktu luang menunggu masa panen. Kelompok pengrajin terdiri atas dua kelompok yaitu pengrajin yang mengolah kain sasirangan untuk perusahaan dan pengrajin yang mengolah kain sasirangan untuk dijual sendiri.

Bagi pengrajin kain sasirangan yang mengolah sendiri dan dijual sendiri memerlukan pemasaran yang lebih luas, karena penjualan masih relatif sedikit. Dengan diberikannya pengetahuan tentang marketing online, pengrajin dapat meningkatkan penjualannya. 


\section{PEMBAHASAN}

\section{METODE}

Sosialisasi ini dilaksanakan sebagai bagian dari Pengabdian pada Masyarakat dilakukan dengan memberikan ceramah dan dialog interaktif untuk mensosialisasikan pemasaran secara online bagi pengrajin sasirangan.

Metode yang digunakan dalam pengabdian ini melalui beberapa tahapan yaitu :

1. Tahap observasi kepada kelompok masyarakat yang akan dijadikan khalayak sasaran yaitu kelompok pengrajin sasirangan.

2. Tahap pelaksanan kegiatan adalah melakukan kegiatan sosialisasi dengan mengikutsertakan partisipasi aktif peserta dengan memberikan petunjuk teknis tentang merancang pemasaran online seperti melalui facebook dan instagram.

3. Tahap evaluasi pelaksanaan yaitu dengan melakukan pengukuran tingkat keberhasilan dari kegiatan sosialisasi marketing online dengan melihat jumlah respon di dunia maya dan peningkatan jumlah permintaan produk.
Berdasarkan pengamatan pada awal pelaksanaan kegiatan penyuluhan menunjukkan minat yang besar dari peserta yang terlihat dari antusiasme para peserta. Pertanyaan yang diajukan para peserta berkenaan dengan cara merancang pemasaran online sangat rinci, dari mempersiapkan akun peserta pada media sosial yang dipilih. Sebagian besar peserta (70 \%) memilih media sosial facebook sebagai media pemasaran online nya.

Pada dasarnya antara Bisnis Online dan Internet Marketing mempunyai kesamaan arti atau makna yang sama yakni sama - sama memiliki tujuan untuk memperoleh penghasilan melalui dunia maya. Namun untuk Internet Marketing lebih berorientasi terhadapat ilmunya atau teknik - teknik mendapatkan uang dari bisnis online tersebut.

Jadi dapat disimpulkan bahwa Internet Marketing adalah suatu ilmu wajib yang digunakan bagi setiap orang yang ingin mengembangkan usaha atau meraih penghasilan dari internet. Dengan mengetahui cara dan strategi internet marketing yang tepat maka Anda akan mengerti dasar dari pemasaran melalui media internet. 
Itulah yang menyebabkan suatu bisnis dapat bertahan atau tetap berjalan walaupun hasil dengan perencanaannya menyimpang adalah dari motivasi yang tetap kuat dari wirausahanya.

Dalam pemasaran produk selalu dihadapkan pada keinginan konsumen yang selalu berubah dan munculnya pesaing-pesaing pada produk sejenis. Bahkan bisa jadi bermunculan produk sejenis dengan kualitas yang lebih baik.

Ketika produk sudah tersedia dan terkumpul dalam jumlah yang banyak, pengrajin akan kebingunan menentukan kemana menjualnya dan siapa calon pembelinya. Sehingga perlu dirancang perencanaan pemasaran yang baik berkenaan dengan bentuk produknya, berapa harganya, dimana menjual dan bagaimana memperkenalkannya kepada khalayak. Dengan demikian, pengrajin dapat menentukan desain produknya yang sesuai keinginan calon pembeli dan menetapkan harga yang ekonomis.
Dalam materi sosialisasi sudah dijelaskan kepada peserta tentang pemasaran online, dan bagaimana merancang tampilan foto produk untuk dikenalkan secara virtual melalui akun facebook. Bagi pengrajin/anggota keluarganya yang sudah memiliki akun tinggal diarah untuk memperbaiki tampilan laman akun masing-masing, sudah $60 \%$ pengrajin bersedia untuk menyiapkan akun medsos nya.

Evaluasi berikutnya dilaksanakan setelah kegiatan sosialisasi dan demontrasi perancangan pemasaran produk melalui internet yang diberikan kepada peserta kegiatan. Indikator yang digunakan untuk mengukur keberhasilan kegiatan ini adalah dengan melihat respon netizen terhadap tampilan foto produk sasirangan dan peningkatan permintaan terhadap produk.

\section{FOTO KEGIATAN}

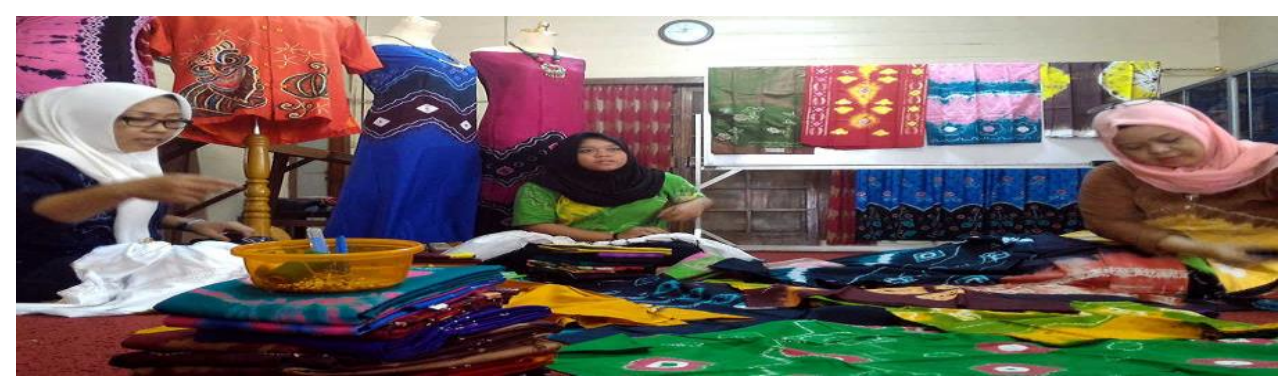

Gambar 1. Merancang produk, dan foto produk untuk di upload 


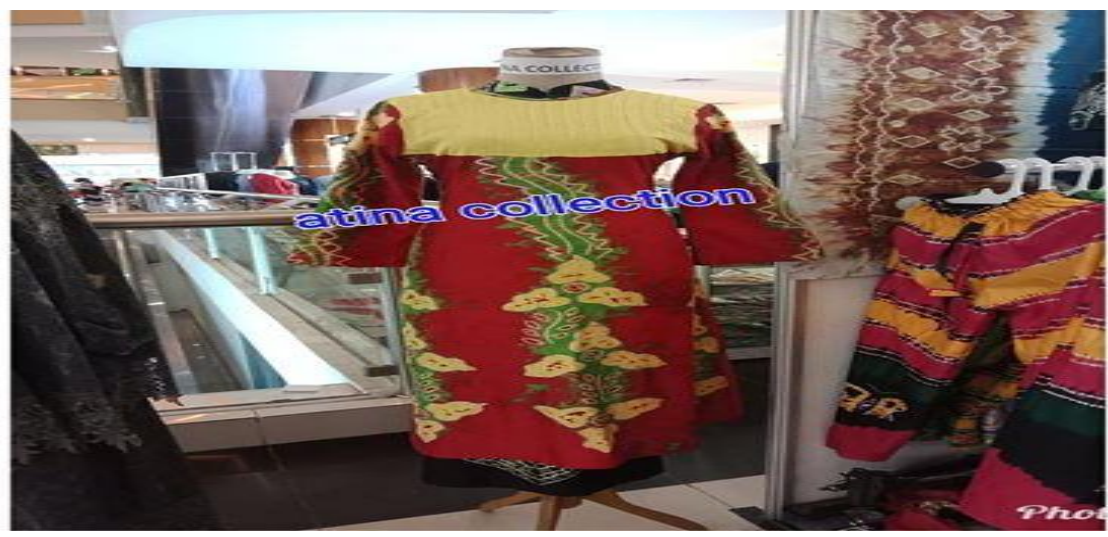

Gambar 2. Contoh tampilan di facebook untuk pemasaran online

\section{KESIMPULAN}

Pada era digital ini, pemasaran online sangat diperlukan bagi industri kecil terutama industri rumah tangga kain sasirangan agar lebih dikenal khalayak dan meningkatkan omzet penjualan. Sebagian besar peserta lebih menyukai memasarkan produk kain sasirangannya melalui akun facebook, karena dianggap lebih popular.

\section{DAFTAR PUSTAKA}

Alma, Buchari. 2004. Manajemen Pemasaran dan Pemasaran Jasa. Bandung: Alfabeta
Bell, Chip.R \& Bilijack.R.Bell. 2004. Magnetic Service: 7 Rahasia Menciptakan Pelanggan Setia. Bandung: Kaifa

Griffits, Andrew. 2002. 101 Taktik Memuaskan Konsumen. Jakarta: Bhuana Ilmu Populer

Franky Slamet; Hetty Karunia Tunjungsari; Mei Ie , 2014, Dasar-Dasar Kewirausahaan: Teori \& Praktik, Buku Kita, Jakarta.

Leonardus Saiman, 2014, Kewiraushaan (Teori, Praktik, dan Kasus-kasus), _ Salemba Empat, Jakarta.

Sunarto. 2006. Prinsip-Prinsip Pemasaran 2. Yogyakarta: UST Peress 